\title{
DE RATIONE DEMONSTRANDI QVA EVCLIDES IN ELEMENTIS VTITVR
}

In Euclidis Elementis quattuor genera demonstrandi reperiuntur. nam non solum deductione et reduetione ad absurdum, sed etiam ratione, quae a mathematicis analytica appellatur, utitur. in quibusdam auter theorematibus probandis methodus, quae inductio completa nominatur, adhibita est $\left.{ }^{1}\right)$. inductio completa primum ab

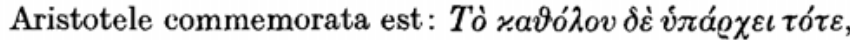

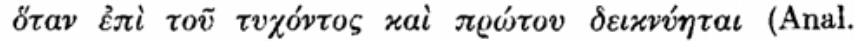
poster. $73 \mathrm{~b} 32$ ).

Ratione analytica Euclides in propositione 17 quinti Elementorum libri utitur. aequaliter ea ratio in appendice prima voluminis quarti (propos. 1-5) reperitur. inductio completa in propositionibus $3,14,17,35$ septimi libri, 13 octavi libri et 8, 9, 20 libri noni adhibita est.

1) Cf. H. Freudenthal, Zur Geschichte der vollständigen Induktion, Archives Internat. d'Histoire des Sciences, Revue trimestrielle de l'Union Intern. d'Hist. d. Sciences, 22, 1953, 17-37. E. S. Stamatis, Uber die vollständige Induktion bei Euklid, Praktika der Akademie Athen, 2, 6, 1953 . 